\title{
Prophylactic use of intraoperative vancomycin powder and postoperative infection: an analysis of microbiological patterns in 1200 consecutive surgical cases
}

\author{
Owoicho Adogwa, MD, MPH, ${ }^{1}$ Aladine A. Elsamadicy, BE, ${ }^{2}$ Amanda Sergesketter, BS, ${ }^{2}$ \\ Victoria D. Vuong, MS, ${ }^{1}$ Ankit I. Mehta, MD, ${ }^{3}$ Raul A. Vasquez, MD, Joseph Cheng, MD, MS, ${ }^{5}$ \\ Carlos A. Bagley, MD, MBA, ${ }^{6}$ and Isaac O. Karikari, MD²

\begin{abstract}
1Department of Neurosurgery, Rush University Medical Center; ${ }^{3}$ Department of Neurosurgery, The University of Illinois at Chicago, Illinois; '2Department of Neurosurgery, Duke University Medical Center, Durham, North Carolina; ${ }^{4}$ Department of Neurosurgery, University of Kentucky, Lexington, Kentucky; ${ }^{5}$ Department of Neurosurgery, Yale University, New Haven, Connecticut; and ${ }^{6}$ Department of Neurosurgery, University of Texas Southwestern, Dallas, Texas
\end{abstract}

OBJECTIVE Wound infections following spinal surgery for deformity place a high toll on patients, providers, and the health care system. The prophylactic application of intraoperative vancomycin powder has been shown to lower the infection risk after thoracolumbar decompression and fusion for deformity correction. The purpose of this study was to assess the microbiological patterns of postoperative surgical site infections (SSIs) after prophylactic use of vancomycin powder in adult patients undergoing spinal deformity surgery.

METHODS All cases involving adult patients who underwent spinal deformity reconstruction at Duke University Medical Center between 2011 and 2013 with a minimum of 3 months of clinical follow-up were retrospectively reviewed. In all cases included in the study, crystalline vancomycin powder was applied to the surgical bed for infection prophylaxis. Baseline characteristics, operative details, rates of wound infection, and microbiological data for each case were gathered by direct medical record review.

RESULTS A total of 1200 consecutive spine operations were performed for deformity between 2011 and 2013. Review of the associated records demonstrated 34 cases of SSI, yielding an SSI rate of $2.83 \%$. The patients' mean age ( \pm SD) was $62.08 \pm 14.76$ years. The patients' mean body mass index was $30.86 \pm 7.15 \mathrm{~kg} / \mathrm{m}^{2}$, and $29.41 \%$ had a history of diabetes. The average dose of vancomycin powder was $1.41 \pm 2.77 \mathrm{~g}$ (range 1-7 g). Subfascial drains were placed in $88 \%$ of patients. All SSIs occurred within 30 days of surgery, with deep wound infections accounting for $50 \%$. In $74 \%$ of the SSIs cultures were positive, with about half the organisms being gram negative, such as Citrobacter freundii, Proteus mirabilis, Morganella morgani, and Pseudomonas aeruginosa. There were no adverse clinical outcomes related to the local application of vancomycin.

CONCLUSIONS Our study suggests that in the setting of prophylactic vancomycin powder use, the preponderance of SSIs are caused by gram-negative organisms or are polymicrobial. Further randomized control trials of prophylactic adjunctive measures are warranted to help guide the choice of empirical antibiotic therapy while awaiting culture data.

https://thejns.org/doi/abs/10.3171/2017.2.SPINE161310

KEY WORDS vancomycin; antibiotics; prophylaxis; surgical site infection; spine surgery; microbial pattern

$\mathrm{T}$ HE reported incidence of postoperative surgical site infections (SSIs) following lumbar spine surgery ranges from $0.7 \%$ to $12 \% .{ }^{22,25,36,40}$ SSIs can lead to increased patient and provider burden, with prolonged hospital stays, need for further surgical interventions, readmission, and delayed rehabilitation., ${ }^{2,516,22,46}$ Addition- ally, studies have shown that postoperative SSIs are correlated with elevated mortality risk ${ }^{22,23}$ and increased health care costs. ${ }^{8,12,26}$ Given the high incidence of SSIs after lumbar decompression and fusion procedures, locally applying prophylactic antibiotics (i.e., vancomycin powder) was introduced as an adjunct to standard systemic antibiotic

ABBREVIATIONS ACS NSQIP = American College of Surgeons National Surgical Quality Improvement Program; $A F i b=$ atrial fibrillation; $B M I=$ body mass index; CAD = coronary artery disease; $\mathrm{CDC}=$ Centers for Disease Control and Prevention; $\mathrm{CKD}=$ chronic kidney disease; $D V T$ = deep vein thrombosis; IQR = interquartile range; IV = intravenous; MRSA = methicillin-resistant Staphylococcus aureus; PE = pulmonary embolism; SSI = surgical site infection; UTI = urinary tract infection.

SUBMITTED November 11, 2016. ACCEPTED February 23, 2017.

INCLUDE WHEN CITING Published online June 30, 2017; DOI: 10.3171/2017.2.SPINE161310. 
prophylaxis with the hope of decreasing postoperative infection rates.

Vancomycin powder provides broad coverage and is available at a low cost, making it an appealing option as an adjunct for perioperative prophylaxis against postoperative SSIs. Many studies have shown that prophylactic application of vancomycin powder in addition to standard systemic antibiotic prophylaxis leads to a reduction of postoperative deep and superficial SSIs following spinal procedures. ${ }^{6,33,35}$ Sweet et al. ${ }^{44}$ reported a reduction of postoperative deep wound infections from $2.6 \%$ to $0.2 \%$ in patients undergoing posterior instrumented thoracolumbar spinal fusions. Strom et al. ${ }^{43}$ reported a decrease in infection rate from $10.9 \%$ to $2.5 \%$ in patients undergoing posterior cervical fusion. Adjunctive use of vancomycin powder also has been shown to reduce morbidity and lead to significant health care cost savings..$^{9,14,32}$ However, despite the adjunctive use of vancomycin powder, postoperative SSI after adult deformity surgery remains a serious concern.

The aim of this study was to investigate the incidence, epidemiology, and microbial patterns of postoperative infections among adult patients undergoing spinal deformity surgery in an era of prophylactic vancomycin powder use.

\section{Methods}

\section{Patient Selection}

Approval was obtained from the Duke University Medical Center institutional review board prior to study initiation. Hospital records of adult patients ( $>18$ years of age) who had undergone open posterior spinal decompression and fusion for adult deformity correction between 2011 and 2013 and who had a minimum of 3 months of clinical follow-up were reviewed. Exclusion criteria included traumatic, infectious, and neoplastic causes. Patient demographics, clinical presentation, comorbidities, radiological studies, and all treatment variables were reviewed for each case.

\section{Standard Pre- and Postoperative Systemic Prophylactic Antibiotic Regimen}

All patients received standard systemic antibiotic prophylaxis consisting of intravenous (IV) cefazolin within 1 hour of surgical incision followed by IV cefazolin every 8 hours for 1 day. If the patient was allergic to penicillin, clindamycin was used instead. In rare cases, ciprofloxacin, piperacillin/tazobactam, or vancomycin was used. In all cases, the patients' skin was prepared with chlorhexidine. Fusion levels were determined by preoperative imaging. Before skin closure, irrigation with $2 \mathrm{~L}$ of normal saline by gravity was performed. ${ }^{30}$

\section{Patient Population}

All patients included in the study received $1-7 \mathrm{~g}$ of intraoperative crystalline vancomycin powder spread throughout the wound. The powder was placed directly on the deep wound and subfascial muscle tissues, taking care not to expose bone graft or dura. The surgical approach involved an open midline posterior incision for all patients. Titanium instruments, autograft and demineralized bone matrices, and cortical cancellous chips were used in all cases. Minimally invasive cases were excluded. No patient was lost to follow-up.

The decision of whether to use subfascial drains was based on surgeon preference. However, in most cases $(88 \%)$, subfascial drains were used. In all cases, the wounds were closed with absorbable sutures in the fascia and subcutaneous layers and with staples or suture closure of the skin. After skin closure, incisions were cleaned again with chlorhexidine and a sterile dressing was applied. Dressings and drains were kept in place until the 2nd postoperative day.

\section{Diagnostic Evaluation}

The definition of SSI developed by the Centers for Disease Control and Prevention (CDC) was used to make an SSI diagnosis. ${ }^{29}$ According to the CDC definition, deep space incisional SSIs all occur within 30 days after surgery. Additionally, they involve purulent drainage, isolation of organism, signs or symptoms of infection (such as pain or tenderness, localized swelling, redness, or heat) combined with positive culture results, and diagnosis by a surgeon or attending physician. Thus, for this study, an SSI was defined as being diagnosed during the initial hospitalization or during a hospital readmission or postoperative clinic appointment within 30 days of the surgery.

All patients with a concern for an SSI had standard laboratory tests on readmission to the hospital including erythrocyte sedimentation rates, peripheral white blood cell counts, C-reactive protein, complete urine analysis, and microbiology and blood cultures. The erythrocyte sedimentation rate was determined by the Westergren method and considered abnormal if greater than $15 \mathrm{~mm} /$ hour. The C-reactive protein level was considered abnormal if greater than $5 \mathrm{mg} / \mathrm{dl}$. Bacterial identification and susceptibility testing were performed according to the CDC guidelines. ${ }^{30}$

\section{Clinical Parameters}

Preoperative, intraoperative, and postoperative data for each patient were collected from the medical records. Surgical infection risk factors were documented for each patient, including body mass index (BMI), smoking status, albumin level, chronic kidney disease (CKD), hyperlipidemia, coronary artery disease (CAD), atrial fibrillation (AFib), anemia, and diabetes mellitus. Pertinent operative details were also collected, including operative time, estimated blood loss, duration, number of levels instrumented, subfascial drain use, number of subfascial drains, volume of irrigation, average dose of vancomycin powder, nerve root injury, spinal cord injury, and durotomy. Postoperative variables included length of stay, urinary tract infection (UTI), delirium, ileus, motor weakness, sensory deficits, other infections, deep vein thrombosis (DVT), pulmonary embolism (PE), anemia requiring transfusion, number of days from discharge to readmission, and readmission source.

\section{Statistical Analysis}

Parametric data were expressed as means \pm standard 
TABLE 1. Baseline preoperative variables for patients developing postoperative infections

\begin{tabular}{lc}
\hline \multicolumn{1}{c}{ Variable } & Value \\
\hline No. of pts w/ postop infection & 34 \\
\hline Male $(\%)$ & 27.00 \\
\hline Mean age at op $(\mathrm{yrs})$ & $62.08 \pm 14.76$ \\
\hline Mean BMl $\left(\mathrm{kg} / \mathrm{m}^{2}\right)$ & $30.86 \pm 7.15$ \\
\hline Smoker $(\%)$ & 17.64 \\
\hline CKD $(\%)$ & 5.88 \\
\hline Hyperlipidemia $(\%)$ & 44.15 \\
\hline CAD (\%) & 5.88 \\
\hline AFib (\%) & 17.64 \\
\hline Anemia (\%) & 26.47 \\
\hline Diabetes (\%) & 29.41 \\
\hline Mean serum albumin level $(\mathrm{g} / \mathrm{dl})$ & $3.9 \pm 0.34$ \\
\hline
\end{tabular}

Pts $=$ patients.

Mean values are given with SDs.

deviation and compared via Student t-test. Nonparametric data were expressed as median and interquartile range (IQR) and compared via the Mann-Whitney U-test. All tests were 2-sided, and results were considered statistically significant if the $\mathrm{p}$ value was less than 0.05 . All statistical analysis was performed using JMP, version 12 (SAS Institute Inc.).

\section{Results}

Among the 1200 consecutive operative spine cases performed for adult spinal deformity between 2011 and 2013, 34 cases of SSI (2.83\%) were identified. The average age of patients who developed SSI was $62.08 \pm 14.76$ years (Table 1). Of the patients who developed an SSI, $27 \%$ were male. The average BMI of patients who developed an SSI was $30.86 \pm 7.15 \mathrm{~kg} / \mathrm{m}^{2}$, and $17.64 \%$ of patients who developed an SSI were smokers. Two of the patients who developed an SSI had CKD, 2 had CAD, and 6 had AFib; 15 (44.15\%) had hyperlipidemia, 9 (26.47\%) had anemia, and $10(29.41 \%)$ had diabetes. The average albumin level was $3.9 \pm 0.34 \mathrm{~g} / \mathrm{dl}$.

In patients who developed an SSI, the average operative time was $352.16 \pm 170.29$ minutes (Table 2). The mean estimated blood loss was $1733.82 \pm 1604.27 \mathrm{ml}$. The median number of levels fused was 7 (IQR 4-8). Subfascial drains were used in $88.00 \%$ of patients; the median number of drains used was 1 (IQR 1-2). The average volume of irrigation was $2.73 \pm 2.42 \mathrm{~L}$, and the average dose of vancomycin powder used was $1.41 \pm 2.77 \mathrm{~g}$. There were no incidences of nerve root injury or spinal cord injury in patients who developed an SSI, but $44.15 \%$ of patients underwent a durotomy.

The average length of stay for patients who had a postoperative SSI was $9.36 \pm 7.59$ days (Table 2). Two (5.88\%) of the patients with an SSI had a UTI postoperatively, and $2(5.88 \%)$ developed other postoperative infections. Delirium, ileus, and motor weakness each developed postoperatively in 3 patients $(8.82 \%)$. Postoperative sensory deficits developed in 1 (2.94\%) patient. There were no incidences of postoperative DVT or PE. Of the 34 patients who devel-
TABLE 2. Operative and postoperative variables

\begin{tabular}{|c|c|}
\hline Variable & Value \\
\hline \multicolumn{2}{|l|}{ Operative variables } \\
\hline Mean operative time (mins) & $352.16 \pm 170.29$ \\
\hline Mean EBL (ml) & $1733.82 \pm 1604.27$ \\
\hline \multicolumn{2}{|l|}{ Fusion levels } \\
\hline Median & 7 \\
\hline IQR & $4-8$ \\
\hline Subfascial drains used (\%) & 88.23 \\
\hline \multicolumn{2}{|l|}{ No. of subfascial drains } \\
\hline Median & 1 \\
\hline IQR & $1-2$ \\
\hline Mean vol of irrigation $(\mathrm{L})$ & $2.73 \pm 2.42$ \\
\hline Mean dose of vancomycin powder (g) & $1.41 \pm 2.77$ \\
\hline Nerve root injury (\%) & 0.00 \\
\hline Spinal cord (\%) & 0.00 \\
\hline Durotomy (\%) & 44.15 \\
\hline \multicolumn{2}{|l|}{ Postoperative variables } \\
\hline Mean LOS (days) & $9.36 \pm 7.59$ \\
\hline UTI (\%) & 5.88 \\
\hline Delirium (\%) & 8.82 \\
\hline lleus (\%) & 8.82 \\
\hline Motor weakness (\%) & 8.82 \\
\hline Sensory deficits (\%) & 2.94 \\
\hline Other infection (\%) & 5.88 \\
\hline DVT (\%) & 0.00 \\
\hline PE (\%) & 0.00 \\
\hline Anemia requiring transfusion (\%) & 64.70 \\
\hline $\begin{array}{l}\text { Mean no. of days from discharge to } \\
\text { readmission }\end{array}$ & $15.61 \pm 8.43$ \\
\hline Readmission source: home (\%) & 73.52 \\
\hline
\end{tabular}

$\mathrm{EBL}=$ estimated blood loss; $\mathrm{LOS}=$ length of stay.

Mean values are given with standard deviations. Percentage values are based on a group size of 34 patients unless otherwise indicated.

oped an SSI, $22(64.70 \%)$ developed anemia that required an allogenic blood transfusion. All of the patients with SSIs were readmitted to the hospital, with $73.52 \%$ being readmitted directly from home. The average number of days from discharge to readmission was $15.61 \pm 8.43$.

Details of each SSI are shown in Table 3. Of the 34 patients who developed an SSI, 17 developed a deep SSI and 17 developed a superficial SSI. The majority of documented infections in both groups were due to either grampositive cocci (other than methicillin-resistant Staphylococcus aureus [MRSA]) in 10 patients or gram-negative rods in 11 patients. There were 2 MRSA infections, and 2 cultures grew multiple organisms. Two patients developed a deep fungal infection (Candida albicans). In 9 cases, the cultures showed no microbial growth, and in 7 of these 9 cases the infections were superficial. The infections were treated only with oral antibiotic therapy in 18 cases, only with IV antibiotic therapy in 13 cases, and with oral and IV antibiotic therapy in 3 cases. The decision to use oral or IV antibiotic therapy was based on the recommenda- 
TABLE 3. Characteristics of acute SSIs following thoracolumbar spine surgery with local vancomycin powder application and subfascial drain placement in each case*

\begin{tabular}{|c|c|c|c|}
\hline Organism & $\begin{array}{l}\text { Depth of } \\
\text { Infection }\end{array}$ & $\begin{array}{c}\text { Antibiotic } \\
\text { Treatment } \\
\text { Route }\end{array}$ & $\begin{array}{c}\text { Irrigation \& } \\
\text { Drainage } \\
\text { Performed }\end{array}$ \\
\hline No growth & Deep & $\mathrm{PO}+\mathrm{IV}$ & Yes \\
\hline MRSA & Deep & $P O+I V$ & Yes \\
\hline C. albicans & Deep & PO & Yes \\
\hline CNS & Deep & PO & Yes \\
\hline P. mirabilis & Deep & IV & Yes \\
\hline P. mirabilis & Superficial & IV & Yes \\
\hline P. mirabilis & Superficial & PO & Yes \\
\hline CNS & Superficial & IV & Yes \\
\hline P. mirabilis & Superficial & PO & Yes \\
\hline CNS & Deep & IV & Yes \\
\hline No growth & Superficial & PO & No \\
\hline No growth & Superficial & PO & No \\
\hline No growth & Superficial & PO & No \\
\hline No growth & Superficial & PO & Yes \\
\hline MSSA & Superficial & PO & Yes \\
\hline MSSA & Superficial & PO & Yes \\
\hline M. morgani & Deep & PO & Yes \\
\hline MRSA & Deep & PO & Yes \\
\hline M. morgani & Deep & PO + IV & Yes \\
\hline$P$. aeruginosa & Deep & IV & Yes \\
\hline No growth & Superficial & PO & Yes \\
\hline Gram-neg rods & Superficial & IV & Yes \\
\hline MSSA & Deep & PO & Yes \\
\hline No growth & Superficial & PO & Yes \\
\hline MSSA & Deep & IV & Yes \\
\hline MSSA & Deep & IV & Yes \\
\hline $\begin{array}{l}\text { Beta-hemolytic Streptococcus } \\
\text { Group B }\end{array}$ & Deep & IV & Yes \\
\hline C. albicans & Deep & PO & Yes \\
\hline Klebsiella + C. freundi & Deep & IV & Yes \\
\hline Gram-neg rods + diphtheroids & Superficial & IV & Yes \\
\hline No growth & Superficial & IV & Yes \\
\hline No growth & Deep & IV & Yes \\
\hline P. mirabilis & Superficial & PO & Yes \\
\hline CNS & Superficial & PO & Yes \\
\hline
\end{tabular}

CNS = coagulase-negative Staphylococcus; MSSA = methicillin-sensitive $S$. aureus; neg = negative; $\mathrm{PO}=$ per os (by mouth).

* SSls occurring within 30 days of surgery.

tion of the infectious disease team. Irrigation and drainage was performed for the majority of infections; 3 of the 17 patients with superficial SSIs did not undergo incision and drainage.

\section{Discussion}

In this retrospective study, we demonstrate that in the setting of prophylactic vancomycin powder use, the pre- ponderance of SSIs occurring after lumbar decompression and fusion for deformity correction are caused by gramnegative organisms or multiple organisms.

The low incidence of SSI after spinal surgery with use of prophylactic vancomycin powder has been extensively reported. In a retrospective case series of 981 patients undergoing spinal surgery conducted by Ghobrial et al., ${ }^{11}$ $5.1 \%$ of patients who received vancomycin powder in the wound bed were diagnosed with an SSI with a positive wound culture. In a retrospective study of 389 patients undergoing instrumented spine surgery, Dennis et al. ${ }^{9}$ reported an infection rate of $0.8 \%$ among patients who were prophylactically treated with local vancomycin powder. Strom et al. ${ }^{43}$ reported a wound infection rate of $2.5 \%$ after posterior cervical fusion with local application of vancomycin powder in a retrospective study of 171 patients. In a meta-analysis of 10 studies totaling 2574 patients undergoing spinal surgery performed by Khan et al., ${ }^{21}$ a composite infection rate of $1.3 \%$ was observed in patients who received intraoperative vancomycin powder. The observed infection rate in the present study (2.4\%) appears well within the previously reported range.

Demographic factors, including obesity and preoperative malnourishment, as well as operative variables, such as the number of fusion levels, increase the risk of SSI after spinal surgery. In a retrospective analysis of $3353 \mathrm{pa}-$ tients undergoing single-level lumbar fusion in the American College of Surgeons National Surgical Quality Improvement Program (ACS NSQIP) database, Lim et al. ${ }^{28}$ reported that obesity led to increased risk of postoperative SSI. Increased risk of infection with BMI $>30$ has been extensively reported in other studies, $7,17,20,31,39,41$ a trend that likely influenced our cohort's risk of developing SSI due to our observed average BMI of $30.86 \pm 7.15 \mathrm{~kg} / \mathrm{m}^{2}$.

Malnourishment also affects infection risk after spinal surgery. In a retrospective study of 19 consecutive patients treated for wound infections after spinal surgery, Stambough and Beringer ${ }^{42}$ found that a majority of infections occurred in malnourished patients with low albumin levels. In a retrospective review of 4310 cases with data collected prospectively as a component of the ACS NSQIP, Bohl et al. ${ }^{3}$ found that preoperative hypoalbuminemia was a significant risk factor for both wound dehiscence and SSI after lumbar spinal fusion. In their study, the mean preoperative albumin level was $3.95 \pm 0.46 \mathrm{~g} / \mathrm{dl}$ in patients who subsequently developed an SSI. ${ }^{3}$ Similarly, the reported preoperative albumin level in our cohort was on the low end of normal at $3.9 \pm 0.34 \mathrm{~g} / \mathrm{dl}$. Finally, the number of fusion levels influences postoperative infection risk. In a retrospective review of 2309 spine surgeries, Haleem et al. ${ }^{13}$ found that multilevel fusions involving 4-8 vertebrae were associated with greater SSI risk, a range that our average fusion level of 7 falls into. Long operative time and high intraoperative blood loss also likely impacted our cohort's infection risk. ${ }^{9,13,19,27,45}$ Preoperative identification of these risk factors could influence subsequent initiation of empirical antibiotic prophylaxis to reduce the risk of postoperative infections after spinal surgery.

Due to microbial resistance patterns, current antibiotic prophylaxis regimens in spinal surgery are evolving to commonly include local application of vancomycin pow- 
der. Perioperative use of cephalosporins has become commonplace in spinal surgery, ${ }^{9}$ but growing cephalosporin resistance among the common organisms isolated from surgical wound sites, especially MRSA, compromises the efficacy of this approach. ${ }^{24,34,44}$ In fact, nearly $60 \%$ of wound bed isolates including MRSA and S. epidermidis are resistant to cephalosporins. ${ }^{44}$ To counteract this growing cephalosporin resistance, the use of intravenous (IV) vancomycin as SSI prophylaxis has been studied. ${ }^{10}$ However, IV vancomycin has not been shown to be superior to IV cephalosporin treatment for SSI prophylaxis. ${ }^{10}$ Furthermore, studies have shown that systemic IV antibiotics have limited penetration into the spinal cord and consequently must be administered at supratherapeutic doses, posing an increased risk of systemic side effects including hypotension and nephrotoxicity. ${ }^{37}$

In an era of SSIs caused by cephalosporin-resistant gram-positive organisms, local intraoperative application of vancomycin powder has become an attractive alternative for antibiotic prophylaxis. Unlike IV vancomycin, locally applied vancomycin powder is not absorbed systemically and thereby poses minimal risk of systemic side effects. ${ }^{6,44}$ This lack of systemic absorption has also been proposed to be the mechanism for the increased antimicrobial action of vancomycin powder, as a higher concentration remains in the wound bed to provide prophylaxis against microbial growth. ${ }^{16}$ Furthermore, vancomycin powder has been shown to be more efficacious against two of the most common isolates in SSI, MRSA and S. epidermidis, compared with cephalosporin prophylaxis alone. . $^{16,44}$ In a retrospective study of 1732 consecutive thoracic and lumbar posterior spinal fusions, Sweet et al. ${ }^{44}$ found that the addition of local vancomycin powder to an infection prophylaxis regimen of IV cephazolin led to a significant reduction in all postoperative wound infections and led to a complete eradication of SSI involving MRSA or coagulase-negative staphylococcal species. Heller et al. ${ }^{16}$ similarly reported that use of intraoperative vancomycin powder significantly decreased the incidence of acute staphylococcal, deep staphylococcal, and deep MRSA infections in a retrospective study of 342 patients undergoing posterior instrumented spinal arthrodesis. In a meta-analysis of the pooled results of 10 independent studies on the use of vancomycin powder, Chiang et al. ${ }^{6}$ reported that intraoperative vancomycin powder use led to a significant reduction in the incidence of S. aureus SSIs. Similarly, use of vancomycin powder in our cohort led to low rates of infections mediated by gram-positive organisms such as MRSA and coagulase-negative staphylococcal species.

Due to enhanced antimicrobial efficacy against grampositive organisms, the use of intraoperative vancomycin powder may exert a selective pressure that alters the microbiological profile of postoperative wound infections in favor of gram-negative organism colonization. Without vancomycin prophylaxis, the preponderance of SSIs after spine surgery were caused by gram-positive staphylococcal organisms, including MRSA and S. epidermidis. ${ }^{1,15,18,38}$ However, while local application of vancomycin powder decreases gram-positive infections, it also may lead to an increased incidence of gram-negative SSIs after spinal surgery. ${ }^{11}$ In a retrospective study of 981 consecutive patients undergoing spinal surgery with intraoperative application of vancomycin powder, Ghobrial et al. ${ }^{11}$ found that $60.7 \%$ of positive cultures contained gram-negative organisms compared with $21 \%$ in the non-vancomycin powder control group. In their study, the predominant gram-negative organisms included Escherichia coli, Klebsiella pneumoniae, Proteus mirabilis, and Pseudomonas aeruginosa, and $29.4 \%$ of all infections were polymicrobial. ${ }^{11}$ Dennis et al. ${ }^{9}$ also suggested that local application of vancomycin powder led to an altered SSI microbial profile dominated by more gram-negative species. In their retrospective cohort study of 389 patients undergoing instrumented spine surgery, use of vancomycin powder led to increased incidence of $P$. aeruginosa and $K$. pneumoniae-dominated infections. ${ }^{9}$ Similarly, our study showed a predominance of polymicrobial infections as well as infections involving gram-negative organisms, including Citrobacter freundii, P. mirabilis, Morganella morgani, and P. aeruginosa.

The increasing prevalence of gram-negative postoperative infections has led to research into alternative antibiotic prophylaxis regimens to expand antimicrobial coverage. While cephalosporins are typically used to provide gramnegative coverage, cephalosporin-resistant gram-negative organisms are becoming more common in spinal surgery. In a retrospective study of 7529 spinal surgeries, AbdulJabbar et al. ${ }^{1}$ estimated that $61.6 \%$ of all gram-negative infections were caused by cefazolin-resistant organisms. To address growing cephalosporin resistance, Bosco et al. ${ }^{4}$ conducted a retrospective study of 10,084 patients undergoing hip arthroplasty and found that use of expanded gram-negative antimicrobial prophylaxis (weight-based gentamicin or aztreonam treatment) significantly decreased cephalosporin-resistant gram-negative infections and decreased the overall SSI incidence from $1.19 \%$ to $0.55 \%$. Given the changing microbiological profile of SSIs, further studies with customized prophylactic antibiotic regimens addressing evolving pathogen profiles are warranted in spinal surgery. Based on our findings that the use of prophylactic vancomycin powder leads to a predominance of gram-negative SSIs, adding antibiotics with extended gram-negative prophylaxis could also reduce SSI incidence after spinal surgery.

\section{Study Limitations}

This study has limitations, which have implications for its interpretation. First, our small sample size of patients with documented SSIs limits our ability to make any firm conclusions about the efficacy of vancomycin powder or its impact on the SSI microbiological profile. Although pre- and perioperative variables were recorded into a prospective study registry at the time of surgery, these variables were retrospectively analyzed for the purposes of this study, and the study is thus subject to the pitfalls associated with all retrospective reviews. Demographic risk factors were not adjusted for and could have influenced SSI risk and microbial profiles. It is possible that a subset of patients treated at other hospitals for concern of postoperative wound infections were not identified and therefore not included in our series. Subfascial drains have been shown to decrease local vancomycin concentrations and were used in the majority of patients. ${ }^{44}$ Furthermore, 
serum vancomycin concentrations were not collected, and concentrations could have affected subsequent microbial growth. Despite these limitations, this study demonstrates that local application of prophylactic vancomycin powder during spinal surgery leads to a preponderance of gramnegative and polymicrobial SSIs.

\section{Conclusions}

Our retrospective study suggests that in the setting of prophylactic vancomycin powder use, the majority of SSIs are caused by gram-negative or multiple organisms. Based on this changing microbiological profile of SSIs, further randomized control trials are needed to assess the efficacy of additional antibiotic prophylaxis against gram-negative species in reducing incidence of SSI after spinal surgery.

\section{References}

1. Abdul-Jabbar A, Berven SH, Hu SS, Chou D, Mummaneni PV, Takemoto S, et al: Surgical site infections in spine surgery: identification of microbiologic and surgical characteristics in 239 cases. Spine (Phila Pa 1976) 38:E1425-E1431, 2013

2. Basques BA, Varthi AG, Golinvaux NS, Bohl DD, Grauer JN: Patient characteristics associated with increased postoperative length of stay and readmission after elective laminectomy for lumbar spinal stenosis. Spine (Phila Pa 1976) 39:833-840, 2014

3. Bohl DD, Shen MR, Mayo BC, Massel DH, Long WW, Modi $\mathrm{KD}$, et al: Malnutrition predicts infectious and wound complications following posterior lumbar spinal fusion. Spine (Phila Pa 1976) 41:1693-1699, 2016

4. Bosco JA, Catanzano AJ, Stachel AG, Phillips MS: Expanded gram-negative antimicrobial prophylaxis reduces surgical site infections in hip arthroplasty. J Arthroplasty 31:616-621, 2016

5. Campbell RS, Emons MF, Mardekian J, Girgenti D, Gaffney $\mathrm{M}, \mathrm{Yu} \mathrm{H}$ : Adverse clinical outcomes and resource utilization associated with methicillin-resistant and methicillin-sensitive Staphylococcus aureus infections after elective surgery. Surg Infect (Larchmt) 16:543-552, 2015

6. Chiang HY, Herwaldt LA, Blevins AE, Cho E, Schweizer ML: Effectiveness of local vancomycin powder to decrease surgical site infections: a meta-analysis. Spine J 14:397-407, 2014

7. De la Garza-Ramos R, Bydon M, Abt NB, Sciubba DM, Wolinsky JP, Bydon A, et al: The impact of obesity on short- and long-term outcomes after lumbar fusion. Spine (Phila Pa 1976) 40:56-61, 2015

8. de Lissovoy G, Fraeman K, Hutchins V, Murphy D, Song D, Vaughn BB: Surgical site infection: incidence and impact on hospital utilization and treatment costs. Am J Infect Control 37:387-397, 2009

9. Dennis HH, Wei DT, Darren KZ, Shantakumar JT, Kumar $\mathrm{N}$, Lau LL, et al: Is intraoperative local vancomycin powder the answer to surgical site infections in spine surgery? Spine (Phila Pa 1976) [epub ahead of print], 2016

10. Finkelstein R, Rabino G, Mashiah T, Bar-El Y, Adler Z, Kertzman V, et al: Vancomycin versus cefazolin prophylaxis for cardiac surgery in the setting of a high prevalence of methicillin-resistant staphylococcal infections. J Thorac Cardiovasc Surg 123:326-332, 2002

11. Ghobrial GM, Thakkar V, Andrews E, Lang M, Chitale A, Oppenlander ME, et al: Intraoperative vancomycin use in spinal surgery: single institution experience and microbial trends. Spine (Phila Pa 1976) 39:550-555, 2014

12. Godil SS, Parker SL, O’Neill KR, Devin CJ, McGirt MJ:
Comparative effectiveness and cost-benefit analysis of local application of vancomycin powder in posterior spinal fusion for spine trauma: clinical article. J Neurosurg Spine 19:331335,2013

13. Haleem A, Chiang HY, Vodela R, Behan A, Pottinger JM, Smucker J, et al: Risk factors for surgical site infections following adult spine operations. Infect Control Hosp Epidemiol 37:1458-1467, 2016

14. Hatch MD, Daniels SD, Glerum KM, Higgins LD: The cost effectiveness of vancomycin for preventing infections after shoulder arthroplasty: a break-even analysis. J Shoulder Elbow Surg 26:472-477, 2017

15. Hegde V, Meredith DS, Kepler CK, Huang RC: Management of postoperative spinal infections. World J Orthop 3:182189,2012

16. Heller A, McIff TE, Lai SM, Burton DC: Intrawound vancomycin powder decreases staphylococcal surgical site infections after posterior instrumented spinal arthrodesis. J Spinal Disord Tech 28:E584-E589, 2015

17. Higgins DM, Mallory GW, Planchard RF, Puffer RC, Ali M, Gates MJ, et al: Understanding the impact of obesity on short-term outcomes and in-hospital costs after instrumented spinal fusion. Neurosurgery 78:127-132, 2016

18. Horwitz NH, Curtin JA: Prophylactic antibiotics and wound infections following laminectomy for lumber disc herniation. J Neurosurg 43:727-731, 1975

19. Jalai CM, Worley N, Poorman GW, Cruz DL, Vira S, Passias PG: Surgical site infections following operative management of cervical spondylotic myelopathy: prevalence, predictors of occurence, and influence on peri-operative outcomes. Eur Spine J 25:1891-1896, 2016

20. Jiang J, Teng Y, Fan Z, Khan S, Xia Y: Does obesity affect the surgical outcome and complication rates of spinal surgery? A meta-analysis. Clin Orthop Relat Res 472:968-975, 2014

21. Khan NR, Thompson CJ, DeCuypere M, Angotti JM, Kalobwe E, Muhlbauer MS, et al: A meta-analysis of spinal surgical site infection and vancomycin powder. J Neurosurg Spine 21:974-983, 2014

22. Kirkland KB, Briggs JP, Trivette SL, Wilkinson WE, Sexton DJ: The impact of surgical-site infections in the 1990s: attributable mortality, excess length of hospitalization, and extra costs. Infect Control Hosp Epidemiol 20:725-730, 1999

23. Klevens RM, Edwards JR, Richards CL Jr, Horan TC, Gaynes RP, Pollock DA, et al: Estimating health care-associated infections and deaths in U.S. hospitals, 2002. Public Health Rep 122:160-166, 2007

24. Klevens RM, Morrison MA, Nadle J, Petit S, Gershman K, Ray S, et al: Invasive methicillin-resistant Staphylococcus aureus infections in the United States. JAMA 298:1763-1771, 2007

25. Koutsoumbelis $\mathrm{S}$, Hughes AP, Girardi FP, Cammisa FP Jr, Finerty EA, Nguyen JT, et al: Risk factors for postoperative infection following posterior lumbar instrumented arthrodesis. J Bone Joint Surg Am 93:1627-1633, 2011

26. Lamarsalle L, Hunt B, Schauf M, Szwarcensztein K, Valentine WJ: Evaluating the clinical and economic burden of healthcare-associated infections during hospitalization for surgery in France. Epidemiol Infect 141:2473-2482, 2013

27. Lieber B, Han B, Strom RG, Mullin J, Frempong-Boadu AK, Agarwal N, et al: Preoperative predictors of spinal infection within the National Surgical Quality Inpatient Database. World Neurosurg 89:517-524, 2016

28. Lim S, Edelstein AI, Patel AA, Kim BD, Kim JY: Risk factors for postoperative infections following single level lumbar fusion surgery. Spine (Phila Pa 1976) [epub ahead of print], 2014

29. Mangram AJ, Horan TC, Pearson ML, Silver LC, Jarvis WR: Guideline for prevention of surgical site infection, 1999. Infect Control Hosp Epidemiol 20:250-280, 1999 
30. Martin JR, Adogwa O, Brown CR, Bagley CA, Richardson WJ, Lad SP, et al: Experience with intrawound vancomycin powder for spinal deformity surgery. Spine (Phila Pa 1976) 39:177-184, 2014

31. Mehta AI, Babu R, Karikari IO, Grunch B, Agarwal VJ, Owens TR, et al: 2012 Young Investigator Award winner: The distribution of body mass as a significant risk factor for lumbar spinal fusion postoperative infections. Spine (Phila Pa 1976) 37:1652-1656, 2012

32. Milstone AM, Maragakis LL, Townsend T, Speck K, Sponseller P, Song X, et al: Timing of preoperative antibiotic prophylaxis: a modifiable risk factor for deep surgical site infections after pediatric spinal fusion. Pediatr Infect Dis J 27:704-708, 2008

33. Molinari RW, Khera OA, Molinari WJ III: Prophylactic intraoperative powdered vancomycin and postoperative deep spinal wound infection: 1,512 consecutive surgical cases over a 6-year period. Eur Spine J 21 (Suppl 4):S476-S482, 2012

34. Noskin GA, Rubin RJ, Schentag JJ, Kluytmans J, Hedblom EC, Jacobson C, et al: National trends in Staphylococcus aureus infection rates: impact on economic burden and mortality over a 6-year period (1998-2003). Clin Infect Dis 45:1132-1140, 2007

35. O'Neill KR, Smith JG, Abtahi AM, Archer KR, Spengler DM, McGirt MJ, et al: Reduced surgical site infections in patients undergoing posterior spinal stabilization of traumatic injuries using vancomycin powder. Spine J 11:641-646, 2011

36. Pull ter Gunne AF, Cohen DB: Incidence, prevalence, and analysis of risk factors for surgical site infection following adult spinal surgery. Spine (Phila Pa 1976) 34:1422-1428, 2009

37. Rhoten RL, Murphy MA, Kalfas IH, Hahn JF, Washington JA: Antibiotic penetration into cervical discs. Neurosurgery 37:418-421, 1995

38. Rihn JA, Lee JY, Ward WT: Infection after the surgical treatment of adolescent idiopathic scoliosis: evaluation of the diagnosis, treatment, and impact on clinical outcomes. Spine (Phila Pa 1976) 33:289-294, 2008

39. Seicean A, Alan N, Seicean S, Worwag M, Neuhauser D, Benzel EC, et al: Impact of increased body mass index on outcomes of elective spinal surgery. Spine (Phila Pa 1976) 39:1520-1530, 2014

40. Smith JS, Shaffrey CI, Sansur CA, Berven SH, Fu KM, Broadstone PA, et al: Rates of infection after spine surgery based on 108,419 procedures: a report from the Scoliosis Research Society Morbidity and Mortality Committee. Spine (Phila Pa 1976) 36:556-563, 2011
41. Soroceanu A, Burton DC, Diebo BG, Smith JS, Hostin R, Shaffrey CI, et al: Impact of obesity on complications, infection, and patient-reported outcomes in adult spinal deformity surgery. J Neurosurg Spine [epub ahead of print], 2015

42. Stambough JL, Beringer D: Postoperative wound infections complicating adult spine surgery. J Spinal Disord 5:277285, 1992

43. Strom RG, Pacione D, Kalhorn SP, Frempong-Boadu AK: Decreased risk of wound infection after posterior cervical fusion with routine local application of vancomycin powder. Spine (Phila Pa 1976) 38:991-994, 2013

44. Sweet FA, Roh M, Sliva C: Intrawound application of vancomycin for prophylaxis in instrumented thoracolumbar fusions: efficacy, drug levels, and patient outcomes. Spine (Phila Pa 1976) 36:2084-2088, 2011

45. Tominaga H, Setoguchi T, Ishidou Y, Nagano S, Yamamoto T, Komiya S: Risk factors for surgical site infection and urinary tract infection after spine surgery. Eur Spine J 25:3908-3915, 2016

46. Weber WP, Zwahlen M, Reck S, Feder-Mengus C, Misteli H, Rosenthal R, et al: Economic burden of surgical site infections at a European university hospital. Infect Control Hosp Epidemiol 29:623-629, 2008

\section{Disclosures}

Dr. Karikari reports a consultant relationship with NuVasive.

\section{Author Contributions}

Conception and design: Adogwa, Elsamadicy. Acquisition of data: Adogwa, Elsamadicy, Sergesketter. Analysis and interpretation of data: Adogwa. Drafting the article: Adogwa, Sergesketter, Vuong. Critically revising the article: Adogwa, Elsamadicy, Sergesketter, Vuong. Reviewed submitted version of manuscript: all authors. Approved the final version of the manuscript on behalf of all authors: Adogwa. Statistical analysis: Adogwa. Administrative/ technical/material support: Mehta, Vasquez, Cheng, Bagley, Karikari. Study supervision: Adogwa, Cheng, Bagley, Karikari.

\section{Correspondence}

Owoicho Adogwa, Department of Neurosurgery, Rush University Medical Center, 1725 W Harrison, Ste. 855, Chicago, IL 60612. email: owoicho.adogwa@gmail.com. 